\title{
Relationship of erosive gastritis to the acid secreting area and intestinal metaplasia, and the healing effect of pirenzepine
}

\author{
M TATSUTA, H IISHI, AND S OKUDA \\ From the Departments of Gastrointestinal Oncology, and Gastroenterology, The Center for Adult Diseases, \\ Osaka, Japan
}

SUMmary The extent of acid secreting areas and the distribution of intestinal metaplasia in patients with erosive gastritis, and the healing effects of pirenzepine were examined. Studies were done with the endoscopic Congo red-methylene blue test developed in our hospital. Compared with control patients with no gastroduodenal disease, erosive gastritis was associated significantly more frequently with large acid secreting areas, but little or no intestinal metaplasia was detected in the stomach. A double blind trial was carried out, using $100 \mathrm{mg}$ pirenzepine tablets or placebo for three months in 43 patients with erosive gastritis. Endoscopically, complete healing was significantly more frequent in the pirenzepine treated groups three months after the start of the treatment, as compared with the placebo treated group $(\mathrm{p}<0.05)$.

Gastric erosions are frequently seen through the gastroendoscope. A peculiar form of erosive gastritis was described under the name 'gastritis erosiva' by Henning and Schatzki in 1933.' Since then, many reports have been published under such headings as 'varioliform gastritis', 'verrucous gastritis', 'octopus-sucker gastritis', 'gastritis ulcerosa et erosiva', 'complete erosion', and 'mature erosion'.? The pathogenesis of these gastric erosions, however, is still unknown. This disease is frequently associated with duodenal ulcer. ${ }^{3+}$ Moreover, Nesland and Berstad recently, reported that cimetidine was effective in healing gastric erosions. These findings indicate that high acid production may be closely related to the pathogenesis of erosive gastritis.

Pirenzepine is a tricyclic compound developed in West Germany for treatment of peptic ulcers. Acute or chronic treatment with pirenzepine reduces basal and stimulated acid output." Therefore, it seemed likely that pirenzepine is effective in the treatment of erosive gastritis. To test this possibility, we examined endoscopically the extent of the acid secreting areas in patients with erosive gastritis, and the healing effects of pirenzepine.

Address for correspondence: Masaharu Tatsuta. MI). Department of Gastrointestinal Ocology. The Center for Adult Discases. Osaka 3-3, Nakamichi I-chome, Higashinari-ku. Osaka 537. Japan

Received for publication 10 September 1986.

\section{Methods}

\section{PATIENTS}

The extent of acid secreting area and the distribution of intestinal metaplasia were examined in 43 patients with erosive gastritis, and in 66 control patients. Erosive gastritis was defined as multiple raised areas in the gastric mucosa surrounding a small crater like erosion. ${ }^{2}$ Most of the lesions were located in the antrum or the angulus. Control patients were subjects who were suspected of having some gastroduodenal disease from roentogenographic examinations, but who were found to have no localised gastroduodenal lesions on endoscopic examination. Studies were made by the endoscopic Congo redmethylene blue test developed in our hospital. In practice, the procedure was as follows ${ }^{7 x}$ : the patient was given proteinases $(20000 \mathrm{U}$ Pronase, Kaken Pharmaceutical Co, Tokyo, Japan) and $50 \mathrm{ml} 0 \cdot 2 \mathrm{M}$ sodium bicarbonate solution containing $20 \mathrm{mg}$ of dimethylpolysiloxan (Gascon, Kissei Pharmaecutical Co, Matsumoto, Japan) orally, 20 minutes before examination. Ten minutes before endoscopy, $4 \mathrm{mg}$ butropium bromide (Coliopan, Eisai Co, Tokyo, Japan) was injected subcutaneously. A gastroduodenofibrescope was then inserted, gastric juice aspirated, and the interior of the stomach and duodenum inspected. A spray tube was inserted 
through the biopsy forceps channel, and (0.05\% methylene blue solution sprayed over the entire surface of the gastric mucosa. After observation of the fine structure of the gastric mucosa, a mixture of $0.3 \%$ Congo red and $0.2 \mathrm{M}$ sodium bicarbonate solution was sprayed over the gastric mucosa, and the blue discolouration of the gastric mucosa examined. An augmented dose of acid-secreting stimulant $(5 \mu \mathrm{g} / \mathrm{kg}$ of Tetragastrin-NS, Nissui Pharmaceutical Co, Tokyo, Japan) was then administered, and acid secretion observed through the fibrescope for the next five to 15 minutes.

Areas in which the Congo red turned blue-black owing to acid secretion were termed 'discoloured', while those in which the Congo red did not change colour were termed 'non-discoloured'.

Acid secreting areas were classified on the basis of the extent of the discoloured area as follows: (1) Large-discoloured area so extensive that the body of the stomach was completely discoloured; (2) Small-intermediate sized areas of discolouration; and (3) Absent-no discolouration observed.

Biopsy specimens were taken during endoscopy from areas showing positive and negative staining with methylene blue, and from acid secreting and non-acid secreting areas. They were fixed in neutralised $10 \%$ formalin, embedded in paraffin and sectioned at $4 \mu \mathrm{m}$. Sections were stained with haematoxylin and eosin, and examined without any knowledge of their origin.

On the basis of the description by Whitehead et al," the mucosa was classified as oxyntic or pyloric. When only intestinal metaplasia was apparent, the specimens were identified as 'undetermined'. As described by Vilardell," atrophic changes of the gastric mucosa were classified histologically as follows: (1) Superficial gastritis; (2) Atrophic gastritis; and (3) Gastric atrophy.

Patients diagnosed as having erosive gastritis were considered for the study, provided they were within the age range 19-72 years. Patients with ulcer or healed ulcer and other localised lesions in the stomach and duodenum were excluded from consideration. Informed consent was obtained from all patients, and the study was carried out in accordance with the Declaration of Helsinki.

Forty three patients who met the entry criteria were randomly assigned in a double blind fashion to pirenzepine $(25 \mathrm{mg}$ four times daily before each meal and at bedtime) or placebo. The control group received a powdered mixture of $1.0 \mathrm{~g}$ dried aluminum hydroxide gel and $0.5 \mathrm{~g}$ magnesium oxide three times daily 30 minutes after each meal. One gram of the dried aluminum hydroxide was able to neutralise $25 \mathrm{mmol} \mathrm{HCl}$ in an in vitro test. Outpatients visited the hospital once every two weeks, and their consumption of drugs was noted at each visit. Chromoendoscopy was repeated three months after the start of medical treatment by an endoscopist with no knowledge of the patient's treatment. Healing was defined as complete disappearance of all crater like erosions on the raised areas of the mucosa, and erosions were recorded as healed or unhealed.

Statistical analyses were done with the $\chi^{2}$ test." 'Significant' indicates $\mathrm{p}$ value of less than $0 \cdot 05$.

\section{Results}

BIOPSY FINDINGS IN DISCOLOURED AND

NON-DISCOLOURED AREAS

Table 1 summarises the data on biopsy findings in discoloured and non-discoloured areas. All specimens collected from discoloured areas were found histologically to be normal oxyntic gland mucosa, with no fundal gastritis or pyloric mucosa. In contrast, non-discoloured areas were of either pyloric mucosa or oxyntic mucosa altered by atrophic gastritis or gastric atrophy. Therefore, by this test, the oxyntic gland areas can be identified as discoloured.

BIOPSY FINDINGS IN AREAS SHOWING POSITIVE AND NEGATIVE STAINING WITH METHYLENE B L UE

As shown in Table 2, intestinal metaplasia was observed in $135(97 \cdot 8 \%)$ of 138 specimens collected from areas staining with methylene blue. In contrast, intestinal metaplasia was not present in $383(92 \cdot 1 \%)$ of 416 specimens from areas not staining blue. The results indicate that areas of intestinal metaplasia can be identified as areas staining blue with methylene blue. Therefore, on the basis of the size of the areas staining with methylene blue, the distribution of the intestinal metaplasia was classified as follows:

Table 1 Biopsy findings in discoloured and nondiscoloured areas

\begin{tabular}{|c|c|c|}
\hline Histological findings & $\begin{array}{l}\text { Discoloured } \\
\text { area }(\%)\end{array}$ & $\begin{array}{l}\text { Non-discoloured } \\
\text { area }(\%)\end{array}$ \\
\hline \multicolumn{3}{|l|}{ Oxyntic mucosa } \\
\hline Normal & $121(100)$ & ()$(() \cdot())$ \\
\hline Superficial gastritis & $0(0 \cdot())$ & $5(1 \cdot 2)$ \\
\hline Atrophic gastritis & ()$(0 \cdot())$ & $55(12 \cdot 7)$ \\
\hline Gastric atrophy & $0(0 \cdot 0)$ & $30(6.9)$ \\
\hline \multicolumn{3}{|l|}{ Pyloric mucosa } \\
\hline Normal & ()$(() \cdot())$ & ()$(() \cdot())$ \\
\hline Superficial gastritis & ()$(0 \cdot())$ & $12(2 \cdot 8)$ \\
\hline Atrophic gastritis & ()$(0 \cdot())$ & $169(39 \cdot(1)$ \\
\hline Gastric atrophy & ()$(0 \cdot())$ & 9()$(20 \cdot 8)$ \\
\hline \multicolumn{3}{|l|}{ Undetermined } \\
\hline Gastric atrophy & ()$(0 \cdot())$ & $72(16 \cdot 6)$ \\
\hline Total & $121(1()(1)$ & $433(10(1))$ \\
\hline
\end{tabular}


Table 2 Biopsy findings in areas showing positive and negative staining with methylene blue

\begin{tabular}{llc}
\hline \multirow{2}{*}{$\begin{array}{l}\text { Intestinal } \\
\text { metaplasia }\end{array}$} & \multicolumn{2}{l}{ Staining with methylene blue $(\%)$} \\
\cline { 2 - 3 } & Positive & Negative \\
\hline$(+)$ & $135(97 \cdot 8)$ & $33(7 \cdot 9)$ \\
$(-)$ & $3(2 \cdot 2)$ & $383(92 \cdot 1)$ \\
Total & $138(100)$ & $416(100)$ \\
\hline
\end{tabular}

(1) Diffuse-intestinal metaplasia detected along the lesser curvature, and sometimes along the greater curvature, from the antrum to the cardia; (2) Localised-intestinal metaplasia detected in the antrum, or intermediate zone, or gastric body, or around the gastric lesion; and (3) Absent-no intestinal metaplasia.

\section{EXTENT OF ACID SECRETING AREAS AND DISTRIBUTION OF INTESTINAL METAPLASIA IN EROSIVE GASTRITIS}

Table 3 summarises the results on the extent of the acid secreting areas in patients with erosive gastritis, and in control patients. Patients with erosive gastritis were significantly more frequently associated with a large acid secreting area than those without erosive gastritis. In control patients, the acid secreting areas were large in $30(45.4 \%)$, small in $26(39.4 \%)$ and absent in $10(15 \cdot 2 \%)$. In contrast, in patients with erosive gastritis, large acid secreting areas were found in $37(86 \cdot 0 \%)$, and small in six $(14 \cdot 0 \%)$. No patients with erosive gastritis who have no acid secreting areas were seen.

Table 4 summarises the results on the distribution of intestinal metaplasia in patients with and without erosive gastritis. Patients with erosive gastritis were significantly less frequently associated with a diffuse intestinal metaplasia. Diffuse intestinal metaplasia was seen in $14(21 \cdot 2 \%)$ in control patients, but in only three $(7.0 \%)$ in patients with erosive gastritis.

HEALING OF EROSIVE GASTRITIS

Table 5 summarises the data on the healing of erosive gastritis in patients treated with pirenzepine or placebo. All patients were subjected to reexamination at three months after the start of treatment.

Of 20 patients treated with pirenzepine, crater like erosions disappeared in 13 patients $(65 \cdot 0 \%)$. In contrast, erosions disappeared only in six of $23(26 \cdot 1 \%)$ patients who had been treated with placebo $(\mathrm{p}<0 \cdot 05)$. During the observation period, no change in the extent of the acid secreting areas and the distribution of intestinal metaplasia was found in all patients.

Table 6 shows that the patients in the two groups
Table 3 Extent of acid secreting areas in control patients and patients with erosive gastritis

\begin{tabular}{lll}
\hline $\begin{array}{l}\text { Extent of acid } \\
\text { secreting areas }\end{array}$ & $\begin{array}{l}\text { Control } \\
\text { patients (\%) }\end{array}$ & $\begin{array}{l}\text { Patients } \\
\text { with erosive } \\
\text { gastritis (\%) }\end{array}$ \\
\hline Large & $30(45 \cdot 4)$ & $37(86 \cdot 0)$ \\
Small & $26(39 \cdot 4)$ & $6(14 \cdot 0)$ \\
Absent & $10(15 \cdot 2)$ & $0(0 \cdot 0)$ \\
Total & $66(100)$ & $43(100)$ \\
\hline
\end{tabular}

The difference between the incidence of large acid secreting areas in patients with erosive gastritis, and control patients was statistically significant at $\mathrm{p}<0 \cdot(0) 1$. For this analysis, two grades of acid secreting areas were used: large versus small and absent.

Table 4 Distribution of intestinal metaplasia in control patients and patients with erosive gastritis

\begin{tabular}{lll}
\hline $\begin{array}{l}\text { Distribution of } \\
\text { intestinal metaplasia }\end{array}$ & $\begin{array}{l}\text { Control } \\
\text { patients (\%) }\end{array}$ & $\begin{array}{l}\text { Patients } \\
\text { with erosive } \\
\text { gastritis (\%) }\end{array}$ \\
\hline Absent & $32(48 \cdot 5)$ & $30(69 \cdot 8)$ \\
Localised & $20(30 \cdot 3)$ & $10(23 \cdot 3)$ \\
Diffuse & $14(21 \cdot 2)$ & $3(7 \cdot 0)$ \\
Total & $66(100)$ & $43(100)$ \\
\hline
\end{tabular}

Difference between the incidences of absence of intestinal metaplasia in control patients and patients with crosive gastritis was statistically significant at $\mathrm{p}<0.05$. For this analysis, two grades of intestinal metaplasia were used: absent versus localised and diffuse.

Table 5 Healing of erosive gastritis three months after the start of treatment

\begin{tabular}{llll}
\hline Treatment & Patients $(n)$ & No Healing $(n)$ & $(\%)$ \\
\hline Pirenzepine & 20 & 13 & $(65 \cdot 0)^{*}$ \\
Placebo & 23 & 6 & $(26 \cdot 1)$ \\
\hline
\end{tabular}

${ }^{*}$ Difference between the values for patients treated with pirenzepine and placebo was statistically significant at $\mathrm{p}<0.05$.

did not differ significantly with respect to sex distribution, age, proportion of cigarette smokers and alcohol drinkers.

\section{Discussion}

The pathogenesis of erosive gastritis is unknown. Karvonen ${ }^{13}$ reported that maximum acid output (MAO) in patients with active erosions was significantly higher than in controls. Nesland and Berstad, ${ }^{+13}$ however, reported that MAO in patients with grade 2 or 3 erosive prepyloric changes was not significantly different from the values for healthy subjects, but 
Table 6 Clinical characteristics of the patients with erosive gastritis treated with pirenzepine or placebo

\begin{tabular}{ccc}
\hline & $\begin{array}{l}\text { Pirenzepine } \\
\text { group }\end{array}$ & $\begin{array}{l}\text { Placebo } \\
\text { group }\end{array}$ \\
\hline Patients (n) & 20 & 23 \\
Age (yr, mean \pm SE) & $51 \pm 2$ & $52 \pm 2$ \\
Extent of acid secreting & & \\
arcas (\%) & $18(9(1)$ & $19(83)$ \\
Large & $2(10)$ & $4(17)$ \\
Small & $0(0)$ & $0(0)$ \\
Absent & & $15(65)$ \\
Extent of intestinal & $6(26)$ \\
metaplasia $(\%)$ & $2(9)$ \\
Absent & $15(75)$ & $7(30)$ \\
Localised & $4(20)$ & $5(22)$ \\
Diffusc & $1(5)$ & \\
Heavy smoker $(\%)$ & $8(40)$ & \\
( $>40$ cigarettes/day) & & \\
Heavy drinker $(\%)$ & $3(15)$ & \\
(>100 g/day) & & \\
\hline
\end{tabular}

significantly lower than the mean value for patients with duodenal ulcer. Their results are somewhat different from those of Karvonen. ${ }^{12}$ It must be noted, however, that in the study of Nesland and Berstad, healthy subjects were younger than those with erosive prepyloric changes, while Karvonen et al's control group was of comparable age with patients with erosions.

In the present study, we found that, by the endoscopic Congo red-methylene blue test, erosive gastritis was significantly more frequently associated with large acid secreting areas than control patients. In our study, control patients consisted not of healthy subjects but of patients who had been suspected of having gastrointestinal diseases but who were found to be normal on gastroduodenal endoscopic examination. Our findings confirmed a previous report that little or no atrophic gastritis is detected in patients with erosive gastritis." We previously reported a close correlation between the extent of acid secreting areas and acid production.' In general, the more extensive the acid secreting areas, the higher the acid production. Therefore, it seems likely that high acid production may be closely related to the pathogenesis of erosive gastritis.

Nesland and Berstad reported that, in a randomised double blind placebo controlled study of 100 patients with non-ulcer dyspepsia and grade 2 or 3 erosive prepyloric changes, cimetidine was significantly superior to placebo in reducing the grade of erosive prepyloric changes at reendoscopy after four weeks. In the present study, we found that complete healing of erosive gastritis was significantly more frequent in the pirenzepine treated group than in the control group three months after the start of treatment. Cimetidine also significantly reduced epigastric pain after two weeks' treatment, but did not significantly alter any histological features in the specimens from the prepyloric mucosa. ". Vilardell, however, reported that gastroscopic improvement may be associated with a diminution of the inflammatory infiltrates. Sata ${ }^{1+}$ also reported that erosions that were reversible and disappeared histologically consisted of foveolar hyperplasia and inflammatory infiltrates. In the present work we found no change in the extent of the acid secreting area during three months' observation period. Therefore, it is highly questionable whether cimetidine or pirenzepine can prevent recurrence of gastric erosions, and further investigations are required.

André $e t a^{15 \text { in }}$ reported that the improvement of endoscopic features of diffuse varioliform gastritis and immunohistochemical measurements of IgE cells in the mucosa was significantly greater in patients given the mast cell stabilising agent sodium cromoglycate than in those given cimetidine or placebo. They concluded that the disease may have an allergic basis, or at least that type 1 hypersensitivity plays some part in the pathogenesis of the disease and so diffuse varioliform gastritis must be separated from antral varioliform gastritis. In the present study, most of the lesions were located in the antrum or the angulus. We found that pirenzepine was effective for treatment of erosive gastritis in the antrum or the angulus.

\section{References}

1 Henning N, Shatzki R. Gastrophotographishes und roentogenologisches Bild des Gastritis Ulcerosa. Fortschr Geb Roentgenstr 1933; 48:177-85.

2 Vilardell F. Chronic erosive gastritis (valioliform, verrucous gastritis). In: Berk JE, ed. Gastroenterology. Vol 2. Philadelphia: WB Saunders, 1985: 962-4.

3 Green PHR, Fevre DI, Barrett PJ. Hunt JH, Gillespie PE, Nagy GS. Chronic erosive (verrucous) gastritis. A study of 108 patients. Endoscopy 1977; 9: 74-8.

4 Nesland AA, Berstad A. Erosive prepyloric changes in persons with and without dyspepsia. Scand J Gastroenterol 1985; 20: 222-8.

5 Nesland AA. Berstad A. Effect of cimetidine in patients with non-ulcer dyspepsia and erosive prepyloric changes. Scand J Gastroenterol 1985: 20: 629-35.

6 Eberlein W, Schmidt G, Reuter A. Kutter E. Das Ulkustherapeutikum Pirenzepine (LS 519) -eine tricyclische Verbindung mit besondern physikalischchemischen Eigenschaften. Arzneim Forsch 1977; 27: $356-9$.

7 Tatsuta M. Okuda S. Age-related changes in the acidsecreting areas in patients with duodenal ulcer. Endoscopy 1983: 15: 243-5.

8 Tatsuta M. Okuda S. Tamura H, Taniguchi H. Endoscopic diagnosis of early gastric cancer by the endoscopic Congo red-methylene blue test. Cancer 1982; 50: $2956-60$. 
9 Whitehead R, Truelove SG, Gear MWL. The histological diagnosis of chronic gastritis in fiberoptic biopsy specimens. J Clin Pathol 1972; 25: 1-11.

10 Vilardell F. Chronic gastritis. In: Berk JE, ed. Gastroenterology. Vol 2. Philadelphia: WB Saunders 1985: 944-61.

11 Siegel S. Nonparametric statistics for behavioral sciences. New York: McGraw-Hill, 1956.

12 Karvonen AL. Occurrence of gastric mucosal erosions in association with other upper gastrointestinal disease, especially peptic ulcer disease, as revealed by elective gastroscopy. Scand J Gastroenterol 1982; 17: 977-84.
13 Berstad A, Nesland AA. Prepyloric erosions and related changes. Scand J Gastroenterol 1985; 20: 779-82.

14 Sata H. Gastritis erosiva and gastritis verrucosa-Study on morphology and function of varioliform erosions. Gastroenterol Endosc 1974; 16: 365-85.

15 Lambert R, André C, Moulinier B, Bugnon B. Diffuse varioliform gastritis. Digestion 1978; 17: 159-67.

16 André C, Gillon J, Moulinier B, Martin A, Fargier MC. Randomised placebo-controlled double-blind trial of two dosages of sodium cromoglycate in treatment of varioliform gastritis: comparison with cimetidine. Gut 1982; 23: $348-52$. 